\title{
Research on Mobile Marketing Strategy Based on SICAS Model-A Case Study of Yili Group
}

\author{
Liwen Huang \\ School of Management, Jinan University, Guangzhou, China \\ Email: songrenxiaozhen@126.com
}

How to cite this paper: Huang, L.W. (2019) Research on Mobile Marketing Strategy Based on SICAS Model-A Case Study of Yili Group. American Journal of Industrial and Business Management, 9, 1059-1075. https://doi.org/10.4236/ajibm.2019.94073

Received: March 19, 2019

Accepted: April 25, 2019

Published: April 28, 2019

Copyright $\odot 2019$ by author(s) and Scientific Research Publishing Inc. This work is licensed under the Creative Commons Attribution International License (CC BY 4.0).

http://creativecommons.org/licenses/by/4.0/

\section{(c) (i) Open Access}

\begin{abstract}
With the rapid development of mobile communication and electronic technology, the Internet with mobile device has become the most popular way for people to access. Mobile marketing came into being with a distinctive mark. From the perspective of SICAS model, this paper analyzed the concept and status of mobile marketing, and the marketing case of traditional dairy products brand Yili group. Based on literature research, data analysis and field research, this paper comes to the following conclusions for the enterprises: 1 ) Ad content optimization; 2) Ad technology optimization; 3) Communication optimization; 4) Ad placement optimization. This study provides a new perspective on the marketing of mobile Internet.
\end{abstract}

\section{Keywords}

Mobile Marketing, SICAS Model, Advertisement, Yili

\section{Introduction}

Mobile devices and apps not only provide merchants with new channels to reach customers, but also provide the opportunity to combine information search, phone functions and interaction, while also allowing access to shopping, products or services in the store [1]. Mobile devices such as mobile phones and tablets can be regarded as loyal partners of consumers and the gateway to rebuild the relationship between consumers and retailers. They can also effectively supplement the channels for remote sales and physical retail. But due to the limited keyboard, screen size, mobile devices and desktop computers and laptops are different [2], and provide functions such as cameras, scanners, and GPS, which makes different from traditional marketing. Mobile marketing is different from the PC to the Internet.

In Dec. 2018, China's Internet new users have reached 675 million, with an 
annual growth rate of 4.3 percent, and the proportion of Internet users is 81.4 percent, as CNNIC China Internet research center reported. The mobile phone network new users 653 million, accounts for $79.9 \%$ of mobile Internet users, annual growth rate of $5.4 \%$. Mobile internet users maintain faster growth for 5 years, the mobile internet era is in full development. A surge of mobile Internet users, is mainly driven by three forces-mobile communication network construction, the mobile terminal hardware development and the upgrading of mobile applications.

In the mobile internet era, consumers can purchase anytime and anywhere, as well as share their opinions [3]. With the transformation from "on-line" to "always online", the crowd of handheld mobile terminals in changing consumption of time and place, and the research on the mobile marketing model has become the most valuable marketing model, the brand of mobile advertising mainly racks their brains to innovative forms of advertising and marketing communication mode, the third-party advertising platform constantly innovates self-service delivery mode, and continuously optimizes delivery efficiency. Obviously, the era of mobile Internet has its own characteristics, such as personalization, interaction and precision, etc., and the research on mobile marketing has more important practical significance. In the era of mobile Internet, how to combine platform with marketing, what is the distribution mechanism of mobile advertising, and how to use a large amount of data for digital marketing are all problems that this paper will discuss and solve. On the theoretical basis, this paper will also combine the case study of Yili Group, a traditional milk and beverage brand, to try to summarize the advertising and marketing strategies in the mobile Internet era, so as to provide reference for enterprises. This paper also provides a new angle for research in this field to adapt to the current environment and changing audience.

\section{Literature Review}

In terms of literature research, most of researches pay more attention to the discussion of the theory of mobile marketing. There are more than a dozen definitions of "mobile marketing". The most common is the definition defined by the Mobile Marketing Association (MMA) in 2009: mobile marketing refers to a series of marketing practices based on positioning, carried out through mobile devices or networks, and through the form of personalized and customized interaction with consumers, so that enterprises and consumers can communicate with each other [4].

Scholars defined that mobile marketing as a marketing activity in which enterprises use mobile media devices or technologies to communicate with consumers in two or more directions and promote their products. This definition has also gained more recognition [5]. It can be seen that, for mobile marketing, there are several characteristics can be determined: 1) needy for mobile server and internet; 2) two-way communication and interaction with consumers; 3) consumer personality; 4) attain to reach a single consumer. 
In the literature on mobile marketing, American media theorist Paul Levinson has explored the advantages and disadvantages and development prospects of mobile media from the perspective of media research in his works. He points out in the book that its humanization and intellectualization surpass any medium in human history, and calls the mobile phone as the "fifth medium" that surpasses the Internet, showing the strong development potential of mobile media to people [6]. The American scholar Cindy Krum in his 2010 book [7] depicted that panoramic scene in the United States the development of Mobile Internet Marketing, and he detailed lists and Mobile Internet advertising and Marketing is closely related to the technical details including media statistics, provides the domestic scholars on the Mobile Internet advertising and Marketing of the path of the overall impression and related research. In the mobile marketing review of Ström, Vendel and John (2014), consumers are obviously inclined to obtain emotional value and social value in mobile marketing when they accept. Therefore, mobile marketing is a more effective channel than traditional media because it can drive the communication between consumers and brands [8]. American scholars Martin and Booksx (2011) made a more detailed study on the terminal form, marketing mode and applicable industry of Mobile Internet Marketing [9]. Chinese researches pay more attention to the practical application of mobile marketing. In the book of mobile marketing, scholars Feng and Wen (2007) made a specific analysis on the basic theory, operation mode and related technologies of mobile Internet advertising marketing [10]. Dr. Varnali (2010) describes the history and current situation of development of mobile Internet, mobile Internet advertising and marketing platform in China, analyzes the mobile Internet advertising and marketing business model, relatively complete for the mobile Internet advertising and marketing are described [4]. Tiru, Kuusik and Lamp (2010) paid special attention to LBS, the most effective mode of mobile Internet advertising marketing, and analyzed the strategies of LBS advertising marketing, which has certain reference value [11].

When we discuss the marketing communication model, if we want to make a buying decision in the era of traditional media, we generally go through the following five stages: 1) attract consumers' attention (Attention); 2) make consumers interested in goods and services (Interest); 3) cultivate consumers' desire (Desire); 4) make the memory (Memory) and 5) make a purchase action (Action), it is AIDMA marketing mode proposed by Lewis in 1898. Then the international 4A advertising company Dentsu Group proposed “AISAS” law in 2005: Attention, Interest, the Search, Action and Share. In this era, consumers pay more Attention to take the initiative to search information and offer the feedback after the purchase action, this also is the basic characteristics of this times. After the birth of web2.0 era, the marketing method is changing to the "ISMAS" mode in the era of media [12], that is, Interest, Search, mouth, Action and Share. As for the panoramic contact distribution, the SICAS model proposed by DCCI in 2011 is more in line with the movement track of consumption contacts, and has cross-influence on other links. 
At present, some scholars have their own definitions and explanations of mobile marketing, but there is little research literature on this topic in the academic circle, and there are few more detailed Suggestions on how to apply it to brand marketing strategies [13]. At the same time, most of the existing research is on the single definition of "mobile marketing", while the mobile terminals include not only smart phones, but also laptops and tablets. Obviously, the existing research has a certain lag, unable to keep up with the development of technology and unable to meet the market demand. When studying the mobile terminal, we should not single it out or ignore the change of marketing communication mode caused by the ever-changing technology update. After analyzing the current situation of mobile marketing, this paper will start from the perspective of innovative SICAS model to analyze mobile marketing and the spread of mobile advertising from multiple perspectives, which is also the research significance of this paper.

\section{Mobile Marketing Analysis of Yili Based on SICAS Model}

\subsection{SICAS Model}

Commercial marketing has experienced the AIDMA principle in the era of mass media, then the AISAS principle in the era of search engine and the ISMAS model in the era of traditional Internet [12]. Once we actively in the network search information and positive feedback, but are passively accept the brand owners to publicize the information. After the emergence, explosive growth and coverage of mobile intelligent terminals, the advent of the Web2.0 era makes the communication media constantly generalization, and consumers turn to grasp the initiative of information attention, and actively involved in the creation, dissemination and sharing of commercial information.

Through long-term, continuous and real-time monitoring of users by technical means, DCCI finds that the consumption pattern of user behavior in the new era is changing into SICAS pattern. SICAS model is a panoramic model, in which user behavior and consumption trajectory are multi-dimensional interactive processes rather than one-way progressive ones. The full understanding is: brand-users Sense each other, generate Interest-form Interactive, users and brand-merchants establish a connection-Interactive Communication, Action-produce purchase, experience-Share, five stages. In such a communication environment, the enterprise relies on sensors all over the network to perceive and respond to the needs of users in real time, establishes a multi-dimensional interactive foundation between advertising and service, consumes by relying on reliable and convenient entrance, and takes the initiative to be the communicator of advertising.

- Sense-the brand should be perceived. Sense means that users can Sense advertising or marketing content through all internet contactors as Figure 1 displayed. In the SICAS ecology, it is very important to establish a dynamic perception network between brands, merchants and users through distributed and multi-touch. On the one hand, they should be perceived by users; on the other hand, they should be perceived by users. These two points are 
the two keys for brand merchants to establish a perception network. AS for users, click, follow, share, customize, push, automatic matching and location service are all important channels for their effective perception. What brand merchants need to do is to be perceived by users through these channels in the most appropriate way. There are usually awareness rate and amount of perception, arrival rate, understanding, awareness, perceived rate and efficiency rate and so on six measuring index of enterprise awareness, enterprise use around move the Sensor, search by the client, click on the content and accelerometer, real-time sensing user requirements, understand the needs of the users, found its whereabouts, and dynamic response, it is the users, advertisers, mobile terminal enterprise [14].

- Interest \& Interactive-enables users to generate Interest and interact with the brand. It means that after users perceive the existence of the brand in the whole network, it can prompt users to have interest in learning about the brand itself, and at the same time express their attitudes and opinions to the brand side on the social platform to form certain interaction, including the communities, search engines and video sites. The era of Web2.0 is the era of social network. Users resonate on the basis of interest coupling, express their likes and dislikes through the topics, voice volume and concerns, and pay attention to, understand and implement for websites and advertisers. This is represented by the comments section of the mobile advertising page, the fan community and the function of sharing to the social network. After the exposure of content and brand, users express their attitudes through social platforms based on the perception of mobile advertising marketing content, and the word-of-mouth effect is fermented by social groups [15]. In this regard, the effect of marketing information exposure is decreasing, and understanding, following and responding to users' interests and needs become the key, which is also the reason why mobile Internet represented by social network has become the most influential fashion of consumption. On this basis, users will be interested in the content of mobile advertising and interact with each other, and get through different advertising systems, advertising systems, content and service systems.

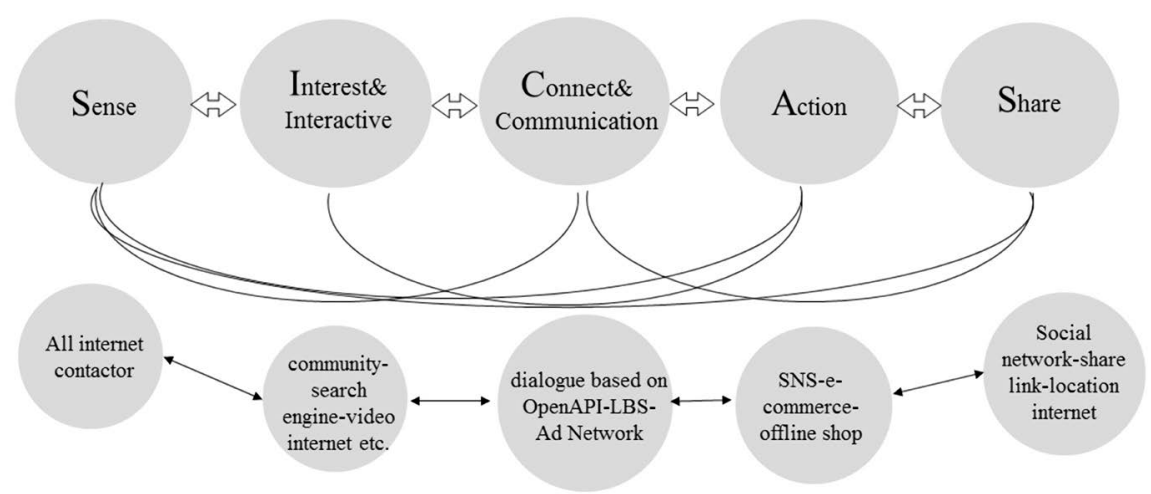

Figure 1. SICAS model (The above is the marketing trajectory, and the following are the elements that mobile marketing needs to leverage at each stage). 
- Connect \& Communication-establish the connection and communication with the brand. Users can connect to branded products or services using Open API, location-based services, and AD networks. To connect and communicate with users and brands, it means to fully integrate advertising, content, relationship network and other aspects, so as to realize the precise delivery of mobile advertising and accurately convey brand information to target consumers. After the unprecedented rapid growth of mobile marketing in 2013, 2014 became the first year of procedural purchase of mobile advertising. Programmatic purchase with crowd as tag brings omnidirectional and massive mobile data resources for enterprises and provides the basis for brand advertisers to realize efficient delivery. Do the following three points: 1) mobile end user data collection. For example, time, duration, location (location-based service), mobile device model and mobile APP used by the user on the mobile terminal. Turn cold data into live people who are valuable to advertisers; 2) get through the channel. The mutual opening of channels such as data collection, game co-movement, e-commerce jump, mobile payment and social platform is conducive to all-around collection of mobile user data, precise delivery and ROI improvement; 3) procedural purchase. Programmatic purchase is to find the target audience in line with the marketing demands on the basis of user data analysis, and realize the purchase of the audience by purchasing the advertising space viewed by the audience. Rely on DSP (demand side platform), Ad Exchange (advertising trading platform) to deliver via RTB (real-time bidding mode) or non-RTB (non-real-time bidding mode).

- Action-purchase action. When users interact and communicate with each other, if they still like this brand, they will purchase it, such as in SNS, Weibo, e-commerce platform or offline store. In the purchase stage, users' behaviors not only occur in e-commerce platforms, but also in O2O, App, social network and corporate official websites. Mobile advertising is just a media platform, which can improve brand exposure and stimulate users' consumption. It still needs multiple page redirects to generate purchase, and users are not willing to consume for this reason. To help brand owners achieve sales transformation, it is necessary to pay attention to the mobile Internet e-commerce layout. Especially in this era, the development of QR code and LBS technology has laid a foundation for "anytime anywhere consumption". The improvement of mobile payment level also provides favorable conditions for offline purchase. Mobile advertising is highly interactive and can be the starting point of purchase on the mobile end, especially in the case of increasing special promotion activities, discounts and group purchase activities on the mobile end. Get through mobile video, mobile e-commerce and mobile payment platforms for integrated marketing. At this stage, the online video website will pay special attention to the connection rate with the e-commerce enterprise platform, as well as the transformation of e-commerce data.

- Share-user experience sharing. After purchase, users can share their own 
experience, which will be spread based on social networks. In the era of Web2.0, Internet users are more inclined to express their personality and attitude. Open sharing not only facilitates word-of-mouth marketing, but also constantly aggregates users' interpersonal relationship chain, so that experience and sharing are no longer the end of consumption, but to a large extent are becoming the source of consumption and an important source of consumption productivity [16]. For user experience evaluation in the era of mobile Internet, brand owners and advertisers should pay more attention to the public opinion of the whole network and make timely response and improvement.

The crazy spread of social network topics is of great benefit to information dissemination, and in recent years there is a growing trend of video. Mobile terminal is the best carrier to promote video socialization. Due to the huge influx of mobile traffic, both online video websites and social platforms have been committed to the development and improvement of mobile client. The combination of video website and social platform extends to the advantages of mobile terminal: 1) bring huge traffic entrance; 2) increase user engagement. Advertisers pay special attention to the user base of video website. Because of the function of interactive sharing in social networking, the click rate of advertisements increases sharply, and the brand exposure is achieved at the speed of viral transmission. Therefore, advertising on this basis is more valuable. For example, Tencent video relies on WeChat public platform, Sina video relies on Weibo platform, and iQIYI relies on Weibo and Baidu post bar; 3) more users' feedback. The social platform is a collection and distribution center of opinions and Suggestions. Through socialization, targeted analysis of advertising effects can be conducted effectively, interactive feedback can be formed with users, and reasonable adjustment can be made to the advertising itself.

\subsection{Marketing Case of Yili Based on SICAS Model}

Yili is China's largest dairy producer and the only Chinese company to have served the Olympic Games and the world expo. The development of Yili brand has gone through decades of development and reform. It has been 26 years since it started its brand operation mode in 1993 and now it has become a world famous brand. Yili group has five business divisions of liquid milk, cold drink, milk powder, yogurt and raw milk, with nearly one hundred subordinate enterprises. It has more than 1000 product varieties including pure milk, milk beverage, ice cream, ice cream, milk powder, milk tea powder and yogurt. The products correspond to different age groups, and the structure basically covers the whole domestic market and all age groups.

According to Admaster's statistics, the main form of mobile marketing carried out by business owners last year was to put in mobile ads, while $81 \%$ of the surveyed brands mainly put in mobile video patch ads, and the quality of patch ads is closely related to the content attraction on video website. Yili has a precise insight into the changes of characteristics in the era of mobile Internet and focuses 
on marketing in media, entertainment and consumption. The most prominent one is the "big variety show project" in recent years: it strives to win sponsorship/naming rights of phenomenal variety shows. Therefore, we can see that Yili's brands occupy a place in the prime-time programs of major TV stations, the front-page programs of major video websites and the topic headlines of major social networking websites. The extension of mobile terminal occupies more traffic to realize brand exposure anytime and anywhere.

As shown in the following Table 1, QQ-star children's milk was named "where are we going, dad?" for the second season, Jindian organic milk, a high-end sub-brand, sponsored "I am a singer" for the fourth season, and Ambrosial, a normal temperature yogurt brand, was named "running man" for the fourth season. All these are the great works of Yili in recent years.

1) Sense. TV show advertisements are linked online and offline. A number of variety shows sponsored by Yili are covered all year round. It makes efforts to convey brand information to users within the perception contacts of the whole network. At the same time, the types of programs cover outdoor reality shows, debate reality shows, cooking show reality rest, indoor competition reality shows, singing competition reality shows and other forms, covering the whole age level. The second season of "Where are we going, dad?" surpassed the first season in terms of TV ratings and network broadcast. The year 2017 was the first year of mobile video commercialization, and the traffic of video on PC was being surpassed by that on mobile. According to Nielsen's ratings and retail data, from the point of the effect of delivery after 2017-Yili QQ star series products in TV advertising in the four years of age or older population won $51.9 \%$ of the arrival rate, that is to say, has a population of 662 million saw the brand information, and at the age of 20 to 35 arrival rate of $55.5 \%$ of the women, involves the population of 99.58 million, in children aged 4 to 14 in the crowd reached more than $60 \%$, nearly one hundred million children through this program to Yili QQ star brand of relevant information.

2) Interest \& Interactive. Mobile propagation is undoubtedly the fastest WeChat. As a QQ iteration product, WeChat coverage and influence has completely killed the previous generation. However, since WeChat does not open the platform data, the spread data of WeChat circle of friends cannot be monitored

Table 1. A list of TV shows sponsored by Yili's brand.

\begin{tabular}{cccc}
\hline Yili Brand & Sponsored Show & Form & Broadcast platform \\
\hline QQ-star children's milk & Where Are We Going, Dad? & Title sponsor & Hunan TV \\
Jindian organic milk & I am a Singer & Title sponsor & Hunan TV \\
Ambrosial greek yogurt & RUNNING MAN (China) & Title sponsor & Zhejiang TV \\
Gulidooats milk & U can U BiBi & Sponsor & iQiyi \\
Weikezichocolate milk TRUMP CARD VS TRUMP CARD & Title sponsor & Zhejiang TV \\
Zhenxiicecream & Please Have the Fridge & Title sponsor & Tencent Video \\
Qiaolezi & About the Big Star & Title sponsor & Tencent Video \\
\hline
\end{tabular}


by the third-party platform. Relative to WeChat, Weibo has lost its former top position, but in terms of its influence on the network, it still ranks top, especially in terms of the influence of event dissemination. Therefore, Yili and other traditional brands still attach importance to the advertisement fermentation ability of microblog. After the end of "dad 2", according to statistics, the total reading amount of the main topic "dad, where are we going?" on Weibo reached 20.9 billion, and the discussion amount exceeded 23 million. Among them, the total reading amount of 114 sub-topics exceeded 7 billion, and the discussion amount exceeded 8.1 million, according to official data of Weibo. At the same time, Yili QQ-star has a staggering 22.4 billion exposures. When the program is broadcast, the program and Yili brand can effectively accumulate their own social assets, which are all digital assets from the social media platform.

3) Connect \& Communication. After collecting the brand digital assets, the cold data collected from the mobile terminal should be transformed into the living people who are valuable to the advertisers to form the portrait of the people. Based on the analysis of social network data, according to the data report provided by Guangzhou big data company, this paper finds that $79.3 \%$ of the audience is female, accounting for $20.7 \%$ of men. Nearly half of all the people come from third-class cities, and only $10.4 \%$ from first-tier cities. Most of the audience aged between 16 and 30, accounting for about $72.3 \%$.

According to the analysis of the crowd, Jindian organic milk will continue to lead the topic on Weibo, deeply embed the brand in the program content, and enhance the correlation between the brand and the program. At the same time, targeted advertising will be placed in the circle of friends for the audience aged 21 - 25, which reflects the precision of mobile marketing incisively and vividly.

4) Action. According to the Nielsen retail data, during the broadcast of "I am a Singer", organic milk accounted for $57.4 \%$ of the overall high-end milk market, firmly holding the position of the top brand in the high-end milk market. This is the result of a series of entertainment marketing plans based on consumer insights. Consumers also responded to the results. In the SICAS model, purchasing behavior is the beginning rather than the end of consumption. It may be products or programs purchased, and the sharing of subsequent experiences starts from purchasing.

5) Share. The official microblog id of "Jindian I am a singer" during the broadcast of the program is mainly about the topic of "Jindian I am a singer", "Jindian's best song" and "heavenly sound" to enhance the interaction between the program and brand fans. During the broadcast of the whole season (from January 15 to April 9, 2017), the volume of voice and interaction of these topics on Weibo performed well. The retweets and interactions with the hashtag \#Jindian were 2.2 million and 3.768 million, respectively.

There is no doubt that the user experience feedback make variety show broadcast to bring huge volume, brand Yili through cooperation with social platform to improve the involvement of the user, to comb the precipitation data of the product sales analysis, competitive analysis and timely public opinion 
monitoring programs and products, and can be adjusted based on the specific steps of marketing and public relations strategy. In the SICAS model, Share is not only the end point of consumption, but also the starting point of influencing the consumption of others.

The above cases show that, compared with other media, social platforms are significantly better than other media in the stages of attracting consumers' attention, generating interest and online sharing. For brand advertisers, in order to better improve the audience's experience of the activity or the brand, they can cooperate with social platforms to more effectively improve the involvement of the audience and improve the word-of-mouth communication of the brand. However, it should be noted that purchasing behavior is the beginning rather than the end of consumption, and social platforms have become an important way for users to share their purchasing experience after purchasing behavior. On the one hand, this kind of sharing is the affirmation and enhancement of the cognition of the purchased products or services; on the other hand, it is the beginning of influencing others' purchasing behaviors.

\section{Discussion}

SICAS model is not only related to social network, but also a behavioral consumption model under the all-network and all-digital environment. Based on this model, enterprises should pay more attention to the precipitation and utilization of data in mobile marketing. At present, mobile advertising is the most mainstream mobile marketing method, favored by most enterprises, but for mobile marketing, they usually only focus on the revenue of advertising platform, which makes them ignore the focus of advertising, the direction of content production and the combination of implantation technology. How to reach target consumers more effectively? In view of this phenomenon, this paper, based on the panoramic model of SICAS, proposes four aspects of strategy optimization: 1) advertising content strategy optimization; 2) advertising technology strategy optimization and 3) communication strategy optimization for business owners as a reference. The following Figure 2 shows the policy structure.

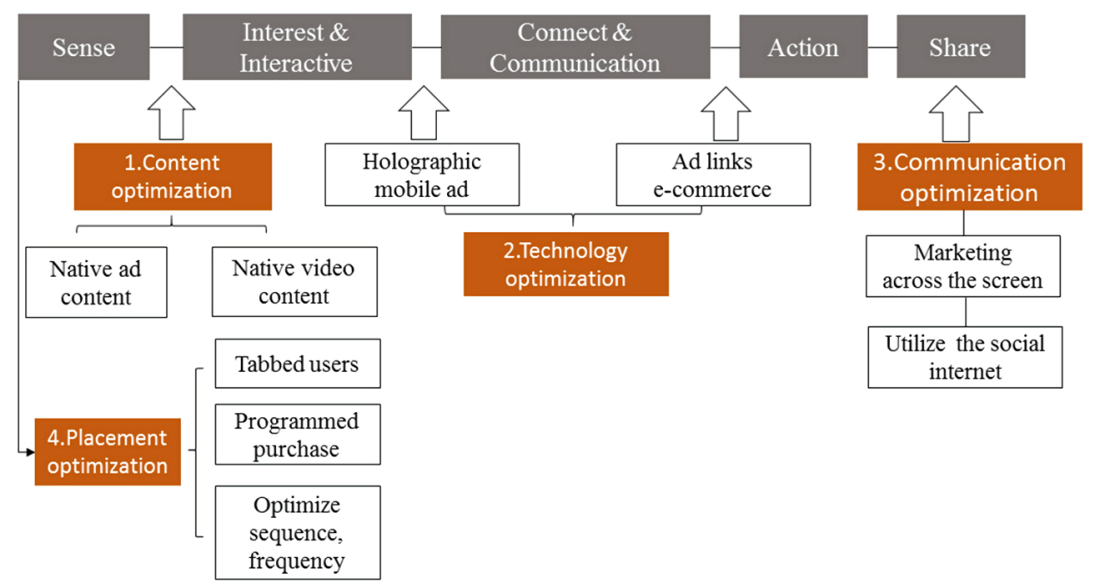

Figure 2. Mobile marketing strategy based on SICAS model. 


\subsection{Ad Content Optimization}

1) Native ad content

Native: the placement and presentation of $\mathrm{AD}$ content does not destroy the harmony of the page itself. In the case of more and more emphasis on the interactive characteristics of mobile end, mobile end advertising should increase the interactive effect. Advertisers can also by moving the accelerometer to implement the interaction with advertising, for example, the audience on the mobile end watching network video ads can prompt "shake, shake go advertising" to stimulate the audience through action to filter the advertisement information, through a simple interactive action, using backward induction can let the audience's interest in and to the brand impression; Then we can mobilize the audience to participate in the production of advertising content. WeChat "shake" snatches red envelopes during the Spring Festival, which arouses the enthusiasm of Chinese TV audience, is a classic case. Dodge automobile company made use of the way to let consumers participate in the interaction to conduct publicity, first through YouTube to give consumers some information tips, according to these information tips, let consumers find the car in the real world, the search process filmed into interesting video, then these video uploaded to YouTube, which caused the spread again. Let consumers personally into, through these strengthen the brand and consumer awareness and communication.

2) Native video content

Under the general trend of network linkage, mobile video advertising relies more and more on professional production content (PGC) with high audience rating, and also creates a large number of revenue on commercial advertising. Brand topic is implanted in the process of video content production. For example, "the voice of China" adds more treasure oral advertising bombing, "extreme challenge" in the Tmall international tailored for an adventure challenge program... Brand owners pay more and more attention to popular video content brand placement. The advantages of low cost, high gross profit and easy content marketing of online video website enable the content and brand to be deeply integrated. On the basis of continuous investment and certain development time, the future self-made content will become an important revenue growth point for online video enterprises.

\subsection{Ad Technology Optimization}

1) Holographic mobile ad

Interactive advertising can better cultivate and improve users' awareness and attitude towards advertising, and the characteristics of mobile devices make more characteristic interactive technologies emerge at the historic moment: using LBS, gravity sensing, voice search and so on, there is a lot of space for the development of new forms of advertising. According to a survey conducted by Madison state, consumers are 6 percent more likely to buy a product after spending half a minute interacting with the $\mathrm{AD}$, and 20 percent more likely to 
buy a product after spending 90 seconds interacting with the $\mathrm{AD}$. The online video advertising experience has three stages, from "seeing" to "appreciating" to "playing". Advertisements should be as relaxing and interesting as possible in terms of both content and form. Only when they are in line with users' media contact motivation can they not be repulsive to users, and they are likely to have the effect of teaching through lively activities and subtle influence. For example, in the interactive game advertisement of cars, users can turn on the lights, open the door, open the skylight and zoom in on the details of the appearance of the car through the touch screen. Meanwhile, LBS can be used to help users navigate to the store. When the Coca-Cola advertisement is broadcast, the coke bottle cap appears on the screen, and the mobile phone starts to vibrate. At this time, you can vigorously shake the mobile phone to grab the Coca-Cola bottle cap in the advertisement. You can grab up to three Coca-Cola bottle caps at a time.

2) Ad links e-commerce

E-commerce websites use mobile advertising to promote their brands, which is conducive to the introduction of mobile App traffic and the connection of e-commerce platforms in these apps, which is conducive to the direct conversion of clicks into purchases. In the current mobile video advertising, the "vision chain" technology can accurately find the target user group on the mobile terminal, and at any time can implant the brand's products into the video watched by these users, and finally buy through the "vision chain" guidance. In the process of viewing, brand products will appear in the corresponding position of video. Users can learn about the detailed information of products by clicking the advertising link, or even directly enter the purchase link. If you see your favorite food in video, you can go to the e-commerce website to buy it at any time. This is a very direct and fast form of advertising click conversion. Users do not need to search back for the commodities they are interested in the video program they have seen. It simplifies the process for users to understand the brand and buy commodities, and improves the click conversion rate of video advertisements. With the increasing number of mobile e-commerce, it is necessary to conduct in-depth cooperation with adaptive e-commerce to build relatively stable e-commerce channels, including the opening of mobile payment platforms.

\subsection{Communication Optimization}

1) Cross-screen marketing

The famous Canadian communication scholar McLuhan pointed out: the media is the message [17]. This phenomenon of one person with multiple screens is transmitting a kind of cross-screen behavior. One is that users may use multiple screens for content consumption at the same time. Second, in order to complete a consumer goal may achieve a variety of screen transfer. In the past two years, with the popularization and deepening of big data, the concept of "cross-screen" has been mentioned, and marketing personnel are also working hard to break through the technical barrier step by step. 
As for Yili in the show, network linkage with big data support for the precipitation mechanism for the user, and then the user is accurate, at the same time in social media and TV platform for joint promotion, through TV, PC, tablet, smart phones, laptops, and other terminal application, showed the advertising and content exposure to the end. Traditional TV has a huge base of users whose viewing habits are not easy to change. However, mobile breaks through the limitations of time and region, and the viewing and sharing anytime and anywhere increasingly diverts users' consumption time in front of TV. Cross-screen communication can wrap the audience more effectively and achieve complementary advantages in crowd coverage and geographical coverage.

2) Utilize the social internet

The most effective way to make a deep memory of information is to participate, so that the audience can fully participate in the advertisement and realize the transformation of the audience's identity: from the information receiver to the product experiencer, product designer or a source of information (sharing mechanism), the effect of advertising can be multiplied under the transformation of social attributes. In 2013, John Doerr put forward the "SoLoMo" mode [18], which means the perfect integration of Social, Local and Mobile. The biggest feature of this mode lies in the web2.0-based Internet marketing, which emphasizes interactive marketing communication based on user value and interaction with users, to realize online and offline integrated marketing strategies through social media. In today's pan-entertainment era, enterprises should fully in the field of entertainment consumption, use the topic effect. Popular program "Chinese good voice" named Shang Stupa, "I am a singer" named quotient set is white, using the content of hot sex, make some interesting, the subject of a rich, continuity, and put them through the BBS, weibo platform such as promotion, to continuously continuous interaction with consumers, make consumers to take the initiative to accept the brand information, then to utilize the entertainment effects of UGC (user-generated content). Short and concise UGC content is very suitable for the viral transmission of social media, such as the ice bucket challenge some time ago, which was fermented by social media in the form of short video and became popular all over the world. The opinion leaders in the target consumer groups are used to make other audiences have deep memory and favorable impression on the brand.

Social platforms are conducive to cross-linking the interpersonal circle of consumers and transforming their social relationships into tangible and analyzable data, so that the final purchase behavior is no longer the end of consumption but the beginning. Also let "share" no longer become ordinary evaluation feedback, but become another part of the beginning of consumption.

\subsection{Ad Placement Optimization}

1) Tabbed users

In SICAS system, the first thing is to perceive the user. Here, tagging refers to:

- Basic characteristics of mobile end users. It includes demographic variables 
such as age, gender and region, as well as the time and place commonly used by mobile end users and mobile access mode.

- Mobile end users accept variables. That is, what are the factors that affect users' acceptance of mobile advertising, such as entertainment sharing, information search and interest? Through basic audience tagging, each brand owner should identify the characteristics of the target users on the mobile end. Using the perception points of the whole network layout such as search engines and social platforms, big data is used to capture the Internet access path of every user and analyze the user portrait after each mobile device: is he or she a male or a female? How old are you? What profession? How about the income? What are your Internet habits? What is your mobile device preference? What is your advertising preference? Watch video ads on your mobile device?

A study by TubeMogul on users in America finds that mobile ads get more clicks because users are more relaxed, especially on tablets. Prime time for iPhone users is between 7 and 10 a.m., while prime time for Android users is in the evening. The highest number of mobile video $\mathrm{AD}$ views came on weekdays, with Tuesday being the peak, followed by Saturday. The completion rate of advertising on weekends was the highest, with an average of $52.2 \%$ and $44.4 \%$ on weekdays, indicating that users were more willing to accept advertisements in the leisure state on weekends [19].

2) Programmed purchase

To improve the accuracy of advertising, this is the most critical link. Psychological primacy effect enlightens us that in the process of social cognition, the first input of information through the "first impression" has an impact on the later cognition of the object, and the first impression formed by the first received information constitutes the core knowledge or memory schema in the brain [20]. After labeling the audience, divide the target customer group of the brand. According to the mobile usage habits of target customers and the search of keywords in the recent period of time, the potential preferred brands and products will be automatically pushed to users. Rely on the emerging means of "programmatic purchase": programmatic purchase basically puts the content of advertisement into the platform that needs to be placed intelligently through a set program, which saves a lot of repetitive labor and greatly improves the efficiency of media purchase. With programmatic purchases, the data can be fed back in real time. Through real-time data feedback, the media strategy is constantly adjusted. Procedural purchase of crowd labels brings enterprises omnidirectional and massive mobile data resources, and provides the basis for brand advertisers to realize efficient delivery.

3) Optimize sequence and frequency

The American psychologist Herbert Krugman has found the three psychological relationships between consumer exposure to advertising: the first is curiosity: "what is this?"; and the second is to know: "what to use?"; the third is judgment: "what impression do you have on the advertisement?" [21]. Considering 
users' perception of advertisements, we should optimize the order of advertising display, the frequency of advertising display and the timeliness of specific advertisements when placing mobile advertisements (especially video advertisements). The first display of mobile advertising has optimal visibility while increasing visibility and visibility decreases with the order. The number of mobile video patch ads accepted by users is usually 3 - 5. In 2013, the most acceptable patch ads for users were 30 seconds. With the purchase intention as the key target of brand building, the maximum effect frequency of video advertisement is $3-8$ times. And some such as more products such as drinks, air conditioning should be paired with to August of the promotion period, the goal of advertising is to cooperate with the product sales season, to effectively increase sales. With the gradual penetration of video on the mobile terminal, the audience's tolerance for advertising time is improving, but the advertising effect reaching rate is still related to the user's acceptance psychology, and the priority ads will still be obtained through the programmed purchase of real-time bidding, so the comprehensive advertising strategy should be optimized.

\section{Conclusions}

The wave of the digital age has pushed mobile devices to the leading position in the consumption scene, and our life has also been fragmented. It has become an irreversible trend that one person holds multiple screens. For this reason, the rapid transformation of consumption mode also makes us think about the change of marketing mode.

SICAS model of mobile marketing makes it difficult to grasp the consumption process. The traditional cognition of the consumption process is no longer suitable at this age, at the same time, due to data mining and data management platform and the existence of advertisement execution platform, it also can be analyzed, because the cold data can be transformed to the visual people, then we can utilize the data to position, production and marketing. There is no doubt that mobile marketing will be a competitive business for years to come. Managers will work hard in data mining to accurately depict consumers and at the same time create marketing types, but the current focus is still on mobile advertising and mobile social platform marketing.

In the field of mobile advertising display, labeling, programming and frequency sequence optimization will become the mainstream. In terms of content, efforts will be made to achieve the original biochemistry to improve consumers' acceptance of advertisements. In terms of technology, more efficient and interactive "implantation" and the opening of e-commerce platforms will be the difficulties to be overcome. In the social platform, cross-screen and multi-terminal will bring new opportunities for advertisers. That is to say, although mobile marketing is the current mainstream mode, cross-screen marketing will be a smarter way for business owners to carry out marketing. Only by using fragmentation and integration of fragmentation can we achieve scale. At the same 
time, the use of entertainment events into the lives of consumers will be more effective.

At present, there are still many problems such as lack of media selection basis, immature data management and delivery technology, but in the next few years, business owners will invest more resources and forces to conquer the commercialization of mobile terminal, and mobile marketing will enter the fast track. Business owners also want to clear positioning for the brand, to foster strengths and circumvent weaknesses.

\section{Conflicts of Interest}

The author declares no conflicts of interest regarding the publication of this paper.

\section{References}

[1] Shankar, V. and Balusbramanian, S. (2009) Mobile Marketing: A Synthesis and Prognosis. Journal of Interactive Marketing, 23, 118-129. https://doi.org/10.1016/j.intmar.2009.02.002

[2] Pedersen, W., Helge, T. and Pierre, B. (2005) Mobilizing the Brand: The Effects of Mobile Services on Brand Relationships and Main Channel Use. Journal of Service Research, 7, 257-276. https://doi.org/10.1177/1094670504271151

[3] Krum, C. (2010) Mobile Marketing: Finding Your Customers No Matter Where They Are. Journal of Consumer Marketing, 28, 239-240.

[4] Varnali, K. and Toker, A. (2010) Mobile Marketing Research: The-State-of-the-Art. International Journal of Information Management, 30, 144-151. https://doi.org/10.1016/j.ijinfomgt.2009.08.009

[5] Venkatesh, S. and Sridhar, B. (2009) Mobile Marketing: A Synthesis and Prognosis. Journal of Interactive Marketing, 23, 118-129. https://doi.org/10.1016/j.intmar.2009.02.002

[6] Levinson, P. (2004) Cellphone: The Story of the World's Most Mobile Medium and How It Has Transformed Everything. Future Survey.

[7] Cindy, K. (2010) Mobile Marketing: Finding Your Customers No Matter Where They Are. Que Publishing.

[8] Ström, R., Vendel, M. and John, B. (2014) Mobile Marketing: A Literature Review on Its Value for Consumers and Retailers. Journal of Retailing \& Consumer Services, 21, 1001-1012. https://doi.org/10.1016/j.jretconser.2013.12.003

[9] Martin, C. and Booksx, I. (2011) The Third Screen: Marketing to Your Customers in a World Gone Mobile. Nicholas Brealey.

[10] Feng, H.P. and Wen, D.F. (2007) Mobile Marketing: The Ultimate Weapon of Marketing. Guangdong Economic Press.

[11] Tiru, M., Kuusik, A. and Lamp, M.L. (2010) LBS in Marketing and Tourism Management: Measuring Destination Loyalty with Mobile Positioning Data. Journal of Location Based Services, 4, 120-140. https://doi.org/10.1080/17489725.2010.508752

[12] Chen, Y.L. and Huang, T.Z. (2012) Mechanism Research of OWOM Marketing Based on SOR and AISAS. Advanced Materials Research, 5, 403-408. https://doi.org/10.4028/www.scientific.net/AMR.441.403

[13] Wang, A. (2011) Branding over Internet and TV Advertising. Journal of Promotion 
Management, 17, 275-290. https://doi.org/10.1080/10496491.2011.596125

[14] Xu, D.J. (2006) The Influence of Personalization in Affecting Consumer Attitudes toward Mobile Advertising in China. Journal of Computer Information Systems, 47, 9-20.

[15] Hampson, S.E., Martin, J., Jorgensen, J. and Barker, M. (2009) A Social Marketing Approach to Improving the Nutrition of Low-Income Women and Children: An Initial Focus Group Study. Public Health Nutrition, 12, 1563-1568. https://doi.org/10.1017/S1368980009004868

[16] Shintaro, O., Akihiro, K. and Mamoru, N. (2007) How Mobile Advertising Works: The Role of Trust in Improving Attitudes and Recall. Journal of Advertising Research, 47, 165-178. https://doi.org/10.2501/S0021849907070195

[17] Mcluhan, M. (1987) The Medium Is the Massage. Management Learning, 18, 25-30. https://doi.org/10.1177/135050768701800104

[18] Hsieh, M.Y. (2018) SoLoMo Technology: Exploring the Most Critical Determinants of SoLoMo Technology in the Contemporary Mobile Communication Technology Era. Journal of Ambient Intelligence and Humanized Computing, 9, 307-318. https://doi.org/10.1007/s12652-016-0375-2

[19] Del Vecchio, P., Di Minin, A., Petruzzelli, A.M., Panniello, U. and Pirri, S. (2018) Big Data for Open Innovation in SMEs and Large Corporations: Trends, Opportunities, and Challenges. Creativity \& Innovation Management, 27, 6-22. https://doi.org/10.1111/caim.12224

[20] Nelson, T.O. (1990) Metamemory: A Theoretical Framework and New Findings. Psychology of Learning \& Motivation, 26, 125-173. https://doi.org/10.1016/S0079-7421(08)60053-5

[21] Krugman, H.E. (1983) Television Program Interest and Commercial Interruption. Journal of Advertising Research, 23, 21-23. 